\title{
Juin 2021
}

\section{Brise sur les Grands Lacs}

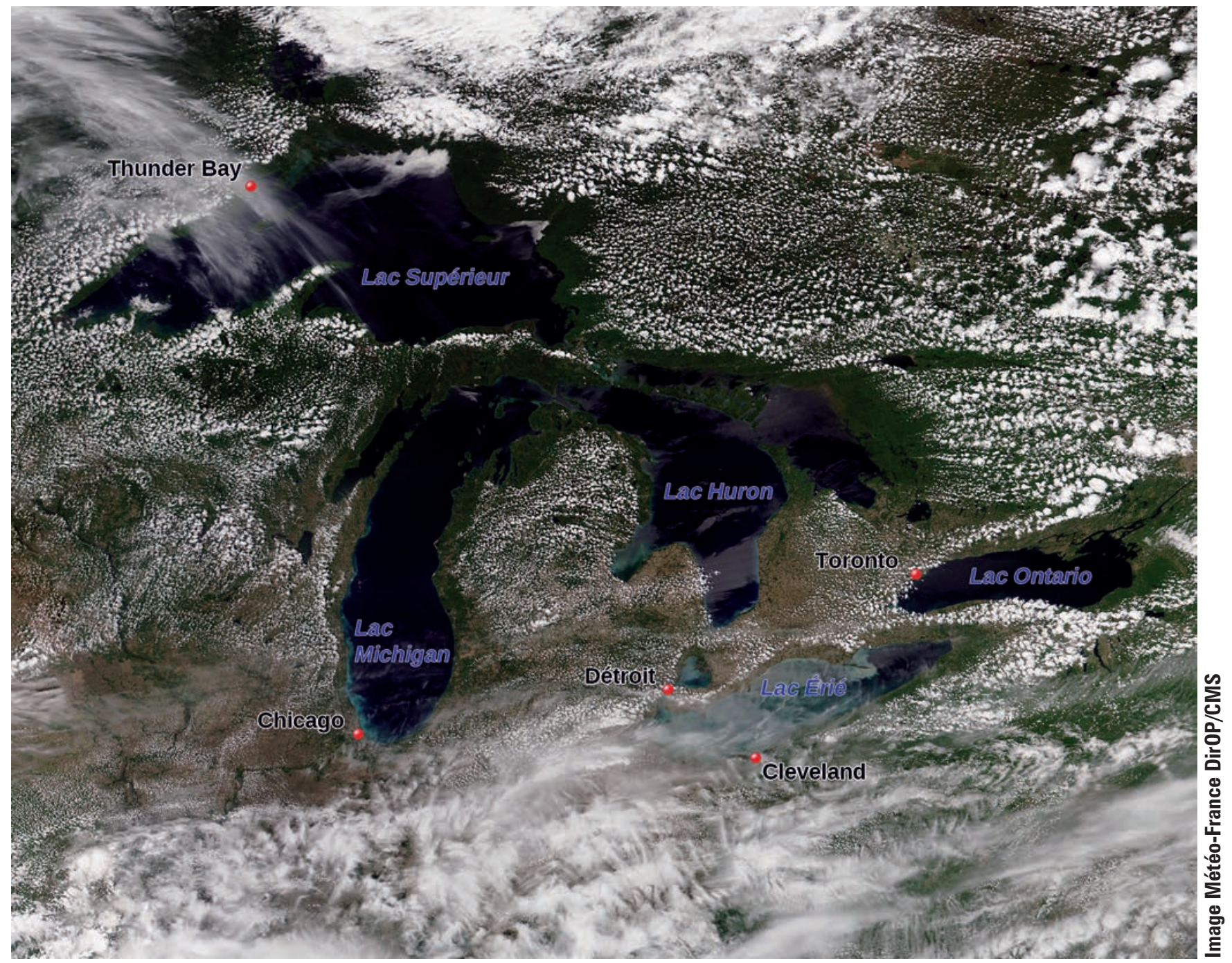

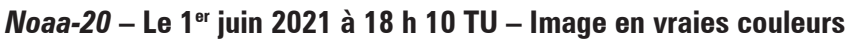

Tune superficie de plus de 240000 km², les G rands Lacs américains constituent le système d'eau douce le plus important au monde en surface après le lac Baïkal en Russie. Ils séparent le nord des États-U nis et le Canada. En ce premier jour de juin, ils sont sous l'influence d'un anticyclone et bénéficient de conditions estivales. Au cours de la journée, le mercure atteint $22^{\circ} \mathrm{C}$ à Cleveland, $23^{\circ} \mathrm{C}$ à Toronto et même $24^{\circ} \mathrm{C}$ à Chicago et $\mathrm{D}$ étroit. La différence de température entre l'eau des lacs et les surfaces continentales est suffisante pour amorcer le phénomène de brise. Durant l'après-midi, la brise souffle perpendiculairement aux rives depuis les lacs vers les terres. Les nombreux cumulus qui se forment à quelques kilomètres des rives sont des marqueurs de ce phénomène. 

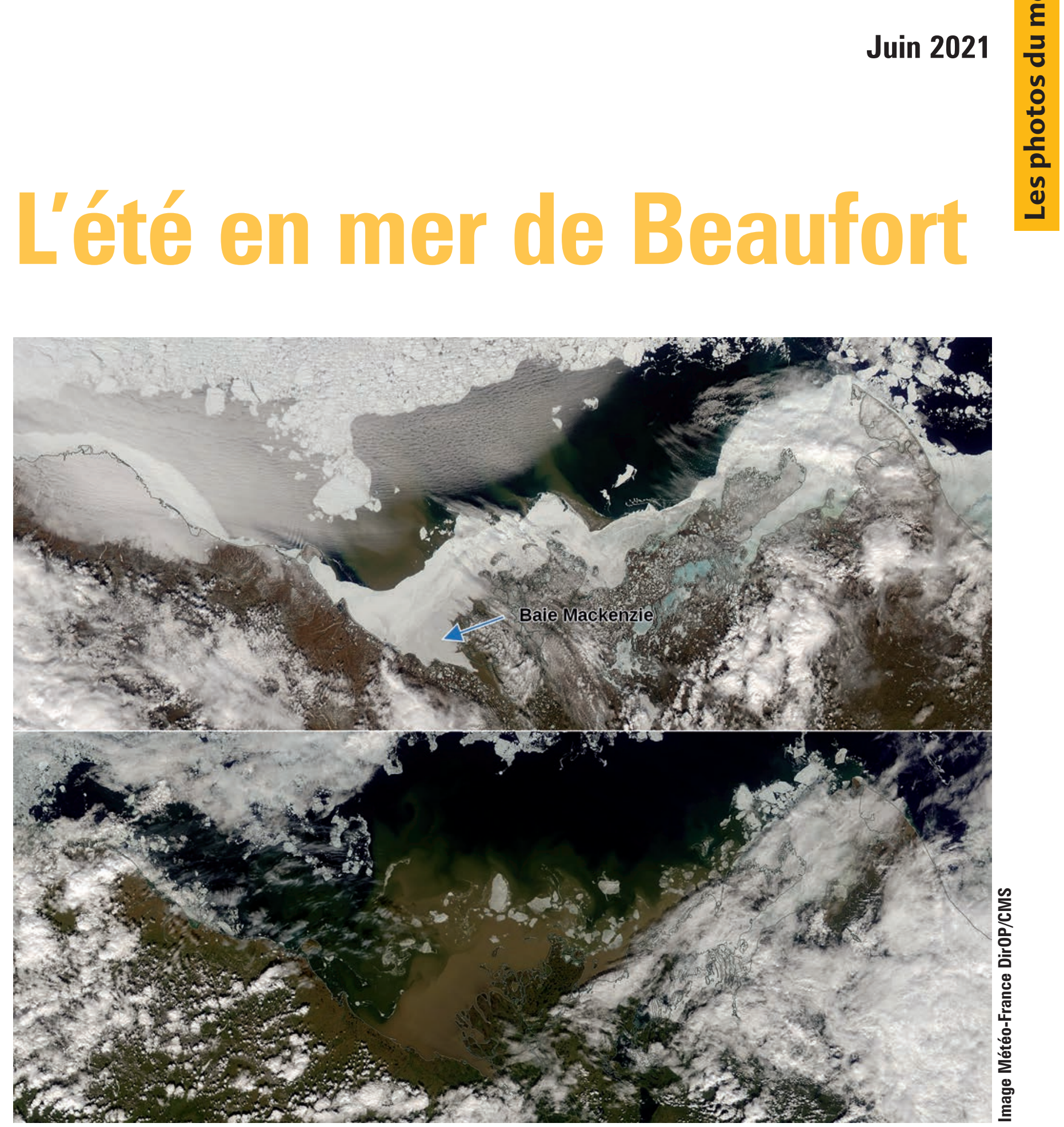

En haut : Aqua - Le 8 juin 2021 à 20 h 55 TU - En bas : Terra - Le 27 juin 2021 à 21 h 10 TU - Image en vraies couleurs

a mer de Beaufort est une partie de l'océan Arctique. Elle s'étend au nord des côtes de l'Alaska (ÉtatsUnis), du Yukon et des Territoires du Nord-O uest (Canada). Seuls 19 jours séparent ces deux images. Le contraste est saisissant. Le 8 juin (image du haut), même si la débâcle a commencé, la glace de mer est nettement visible : sous forme compacte tout au long des côtes, elle couvre entièrement la baie M ackenzie ; plus au large, les alto cumulus translucidus la laissent apparaître sous forme fragmentée. Sur l'image du bas, la glace a presque totalement disparu. Q uelques blocs subsistent à la limite entre les eaux turbides rejetées par le fleuve Mackenzie, dont le débit atteint son maximum annuel, et l'eau de mer d'un bleu profond. La végétation, brune en début de mois, profite du dégel pour verdoyer. 